University of Nebraska - Lincoln

DigitalCommons@University of Nebraska - Lincoln

Faculty Publications, Department of Psychology

Psychology, Department of

June 1977

\title{
Sex and Violence: Can Research Have It Both Ways?
}

Richard A. Dienstbier

University of Nebraska-Lincoln, rdienstbier2@unl.edu

Follow this and additional works at: https://digitalcommons.unl.edu/psychfacpub

Part of the Psychiatry and Psychology Commons

Dienstbier, Richard A., "Sex and Violence: Can Research Have It Both Ways?" (1977). Faculty Publications, Department of Psychology. 221.

https://digitalcommons.unl.edu/psychfacpub/221

This Article is brought to you for free and open access by the Psychology, Department of at DigitalCommons@University of Nebraska - Lincoln. It has been accepted for inclusion in Faculty Publications, Department of Psychology by an authorized administrator of DigitalCommons@University of Nebraska - Lincoln. 
Published in Journal of Communication 27:3 (Summer 1977), pp. 176-188. Copyright (C) 1977 the Annenberg School of Communication; published by Blackwell Publishing. Used by permission. http://www.blackwellpublishing.com/journal.asp?ref=0021-9916

Effects of Television

\title{
Sex and Violence: Can Research Have It Both Ways?
}

\author{
by Richard A. Dienstbier
}

\author{
A personality model approach helps sort \\ out the apparent contradictions between the \\ Pornography and Violence Commission findings.
}

During the last decade, the literature on media exposure has been dominated by a single theoretical system of personality functioning - the social learning model. The model emphasizes that the disinhibition of already-learned behavior, the learning of new behaviors, and the establishment of patterns of personality result from observing the behavior of other people (models) and from vicarious reinforcement upon viewing those models successfully engaging in rewarded sequences of behavior.

It is a tribute to the degree to which social learning oriented psychologists have successfully influenced intellectual and governmental thinking that the model is seldom questioned as providing the appropriate basis for interpreting both the Pornography and Violence Commission reports. The findings and recommendations of the Surgeon General's Scientific Advisory Committee on Television and Social Behavior (hereafter called the Violence Commission) seem to affirm the social learning model, and hence, to be generally believed. The findings and recommendations of the Commission on Obscenity and Pornography (hereafter called the Pornography Commission), on the other hand, do not affirm that social learning model; those findings, therefore, often have been discredited and/or disbelieved.

An alternative to disregarding the research of the Pornography Commission as erroneous or insufficient, of course, is to question the social learning model as the appropriate theoretical framework for interpreting those data. Before discussing how alternative psychological approaches outside of the social learning model can render these two sets of findings non-contradictory, I shall discuss the dif-

Richard A. Dienstbier is Professor and Chairman of the Department of Psychology, University of Nebraska-Lincoln. 
ferent levels of apparent contradiction between the two reports, and the degree to which media specialists, government officials, and social scientists have either focused upon those contradictions or denied or ignored the Pornography Commission findings.

\section{The reports indicated that although media violence led to viewer aggression, exposure to explicit sexuality seemed harmless, possibly reducing sexual deviance.}

The conclusions of the Violence Commission report, entitled Television and Growing Up: The Impact of Televised Violence (31), supported and extended the suggestions of the previous report by the National Commission on the Causes and Prevention of Violence (25). The report concluded that when children grow up watching larger amounts of media violence, they often act more aggressively, not only in childhood, but into adulthood. ${ }^{1}$ Some of the research by Eron and his associates (9) which underlies those conclusions suggested a causal relationship with early (third grade) TV violence viewing leading to aggressiveness ten years later. That relationship was stronger than occurred between any factors associated with parental treatment of the children and later aggressiveness.

The Report of the Pornography Commission (7) was sent to President Nixon and to the Senate and House of Representatives in September, 1970, on the eve of the election. The major response of many of those governmental officials was to condemn the Commission's findings and recommendations (27). The Pornography Commission had reported that exposure of adults to explicit sexual materials had little or no effect upon changing patterns of sexual activity or attitudes about sexuality, that such exposure apparently did not contribute to a decline in moral character or an increase in either general crime rates or sexual crime, and that sexual offenders have generally been underexposed to sexually explicit materials and sexual knowledge during adolescence. The Commission, therefore, recommended the repeal of laws prohibiting adult exposure to explicit sexual materials and recommended increased exposure to sexual knowledge for young people through adequate programs of sex education.

Contradiction results from accepting the popular thesis that for both violence and sexuality, immoral media displays must lead to immoral behavior.

There are two main levels of apparent contradiction between the two reports. At the first level, both explicit sexuality and violence are believed to be evil. The contradiction then results that, while the Violence Commission found media portrayal of its "evil" to cause more "evil" in society, the Pornography Commission denied that media portrayal of its "evil" would increase social "evil."

${ }^{1}$ The term "aggression" is used throughout this paper exclusively to mean behavior (including verbal behavior) which is designed to hurt another individual. 
This equation of sexuality with evil is apparent in statements from a multitude of sources. In his book on Pornography and Politics, Rushdoony (29) stated that both pornography and violence (along with nudism and belief in evolution) are aspects of "primitivism," and that "sadomasochistic themes are also inseparable from pornography." A similar interpretation was quite clearly made in President Nixon's comment of October 24, 1970, about the Pornography Commission's report; he stated, "I have evaluated that report and categorically reject its morally bankrupt conclusions and major recommendations" (27).

Several years later on June 21, 1973, the Supreme Court ruled in five obscenity cases that "in the absence of contrary evidence, the courts of the United States can now assume negative effects of sexually explicit material and they need not be proved by scientific inquiry." In writing the majority opinion in one of the cases, Chief Justice Warren Burger affirmed that a state legislature could act upon the assumption that "commerce in obscene books, or public exhibitions focused on obscene conduct have a tendency to exert a corrupting and degrading impact leading to antisocial behavior" (28). Commenting on that decision several years later in a nationally syndicated newspaper article, James J. Kilpatrick stated that "common sense is a better guide than laboratory experiments; and common sense tells us pornography is bound to contribute to sexual crime. . . . It seems ludicrous to argue 'bad' books do not promote bad behavior" (17).

Broadcasters and federal media regulatory agencies have apparently assumed the equation of both violence and sexuality with "evil." In their code of ethics the National Association of Broadcasters stated that "violence and illicit sex shall not be presented in an attractive manner, nor to an extent such as will lead a child to believe that they play a greater part in life than they do" (21). In a February 1975 report to Congress, although indicating that the TV industry had progressed in protecting children from "violent and sexually oriented material," FCC Chairman Richard E. Wiley urged broadcasters to further protect children from sexual or violent material, regardless of whether such material violated the law (32). In support of this admonition, the FCC cited the Violence Commission report, while ignoring the Pornography Commission's findings. Continuing discussions of this issue in media journals and papers have placed equal emphasis upon what FCC Chairman Wiley has referred to as "gratuitous sex and violence" (6).

\section{The rebuttal to this first apparent contradiction between the two reports is to focus upon the value judgments inherent in these opinions.}

The interpretations of the seemingly contradictory evidence reflect value judgments which seem appropriate in the case of violence, but more complex and questionable in the case of explicit sexuality. It is, of course, difficult to know just how explicitly sexual materials might be defined in terms which do not reflect some value biases. The Pornography Commission itself found the problem sufficient to drop the term "pornography" in their report (7), using instead the phrase "explicit sexual materials"; they did indicate, however, that only 5 percent of all pornographic book 
and magazine content dealt with sadomasochistic, fetishistic, or other "deviant" sexuality. In more recent research published in this Journal, a study of the "adults only" fiction paperbacks which represent "one of the largest areas of pornography production in the United States" indicated that the types of sexual interaction depicted (from 1968 through 1974) still favored heterosexual intercourse between attractive but emotionally uninvolved white participants (30). The facts concerning pornography suggest that such materials should therefore not be considered largely deviant.

It seems mundane but necessary to emphasize that differing value approaches to sex and aggression seem quite appropriate. Sexuality is the force underlying some of society's most venerable institutions, including love, marriage, and reproduction. On the other hand, the expression of tendencies toward aggression and violence must be controlled; it is difficult to think of examples of positive uses of violence. An increased capacity to enjoy, express, and communicate our aggression would not appear to further the well-being of humanity, especially when those activities are considered on an international scale. An answer to this first apparent contradiction between the reports would, therefore, emphasize that pornography and media violence do not equally promote deviancy or do equal harm since normal sexuality and normal aggression are best viewed as quite different in harm or deviance value.

\section{The social learning model suggests a second, less value-laden contradiction-that media presentations of violence and sexuality will similarly encourage interest and imitation.}

A second interpretation of contradiction between the Violence and Pornography Commission findings appears if one takes the behavioristic view that all categories of behavior are learned and maintained through the similar processes of modeling, imitation learning, and reinforcement. Using this approach, we might reason that, if long term attitudinal and/or behavioral changes are due to exposure to media violence, then similar effects must also result from exposure to any other (similar) category of stimulation, especially including pornography.

This notion has been expressed by various authors and social scientists. In a recent article entitled "The Evidence So Far," which appeared in this Journal, George Comstock (8) stated that "the observation of television portrayals can alter the balance between the inclination to perform an act and the inhibitions against such performance on the part of adolescents. Although most of the evidence to date concerns the disinhibition or stimulation of aggression, there is little reason to think the same effect would not occur for other classes of behavior." And in his critical (of pornography) article "Beyond the (Garbage) Pale," Walter Berns (4) wrote, "The pornographers seem to know intuitively what liberals have forgotten, namely, that there is indeed a 'casual relationship ... between words or pictures and human behavior.' At least they are not waiting for behavioral science to discover this fact."

In an article entitled "Sex and Violence: We Can't Have it Both Ways" (3), Leonard Berkowitz suggested a contradiction in the findings of the two Presidential Commissions. The Pornography Commission finding was interpreted to mean that "the portrayal of sexual deviations does not seriously promote simi- 
lar actions" while the essence of Violence Commission ${ }^{2}$ findings were interpreted as meaning that "media violence can induce persons to act aggressively themselves." Berkowitz explained the "contradictory" findings by suggesting that the "seemingly different conclusions were affected, to some extent at least, by a prevailing liberal ideology and its attitudes toward aggression and sex," and "as much by values, ideologies, and biases as by the actual findings."

\section{Based upon the vastly different amounts of prior information, experience, and cultural restrictions, differential impact should he expected from explicit sexuality us. explicit violence.}

The first major problem with our behaviorist social learning model is that the nature of the cultural background upon which the stimulus materials are projected is not considered. Consider the background of frequency of exposure the normal adult or child receives to exaggerated violence as opposed to exaggerated sexual display, and our techniques of socialization of aggression and sexuality. Children are typically trained in a manner which condones both discussion about violence and aggressive play; a walk through any toy store provides some evidence. But an analysis of television programming provides far more compelling support. Relying on Gerbner's research, the Violence Commission (31) found that the rate of violent episodes on television remained relatively steady at about eight per hour from 1967 through 1969. More recently Gerbner and Gross (14) have indicated no substantial change from those earlier figures, "with between six and seven out of every ten leading characters (eight and nine for children) ... still involved in some violence." Given the logic of Gerbner's view (14) that television is the "central cultural arm" of American society, we might expect pro-violence attitudes to prevail in American society. Indeed, surveys of the attitudes of Americans concerning violence (5) indicate that violence is advocated by large segments of our society, if not for social change, then at least to control the potential violence of those who advocate such change.

Sexual interests, discussions, and play, on the other hand, are often discouraged through techniques resulting in the association of guilt, shame, fear, and disgust with sexual activities and topics. These patterns do not change when we consider media exposure. The Pornography Commission reported that "only about 40 percent of adult males and 26 percent of adult females report having seen pictorial depictions of sexual intercourse during the past two years." If we define the ultimate sexual behavior as intercourse or orgasm, our exposure to extreme media violence (killing) is probably greater by hundreds of times than our exposure to extreme explicit sexuality.

However, in real non-media adult life, our relative involvement with sexuality and violence is completely reversed. Few of us have ever seen an individual killed through aggressive violence, and even fewer have perpetrated the violent

${ }^{2}$ The Violence Commission report that was contrasted with the Pornography Commission report was the 1969 report of the National Commission on the Causes and Prevention of Violence; the suggestions made in that report and the findings of the later Surgeon General's Scientific Advisory Committee in 1971 report referred to above are quite similar, however. 
death of another. But most adults consider themselves sexually sophisticated and are (or will be) involved in interpersonal relationships which depend upon sexuality and the ability to communicate and express sexual needs.

We are left, then, to consider the effects that infrequent exposure to explicit sexual materials might have on sexual behavior which is first socialized with a great deal of negativity, but which is supposed to emerge in adulthood as a frequent, positive, and important form of behavior. We might well anticipate that the effects would be quite different from the effects of very frequent media violence exposure on aggressive behavior which is condoned (at least in play form) in childhood, but which must be almost totally suppressed in adulthood.

Focusing upon those typical socialization differences and upon the value differences between "normal" violence (associated with hate and rejection) and "normal" sexuality (associated with passion and acceptance), one can easily anticipate differences in outcome from exposure to either in the media. The research of Gerbner and Gross (14) has demonstrated that a rich diet of televised violence can lead to real fear and the increased expectation of violence; exposure to explicit sexuality, on the other hand, might reduce the associated fear, shame, and guilt which have resulted from direct childhood socialization and from the implied societal message that sexuality is too disgusting to be openly displayed.

\section{This situation becomes even more complex and the behaviorist view becomes more obviously insufficient when we consider the differences in inherent sexual and aggressive dispositions of the human organism.}

Sexual and aggressive tendencies are effectively aroused by different classes of stimuli, developed and sustained differently through the various stages, and released through different arousal-release patterns. If our capacity for or our need for sexuality has a different character than our capacity and need for violence, then this too would influence the impact made by exposure to explicit sexuality or media violence. Such inherent differences do, indeed, seem to exist. Involvement in and capacity for sexual behavior seems more internally determined, being restricted to specific age periods between puberty and old age, and often requiring substantial time intervals between episodes involving orgasm.

By contrast, aggression seems less determined by the limitations of physiological restriction; aggression is more externally determined. ${ }^{3}$ For humans as for most higher animals, there is seldom a survival edge to be gained from seeking out aggressive encounters, but an advantage may be achieved by being aggressive when the external situation calls for that response. Seeking out opportunities

${ }^{3}$ The recognition of those differences in internal vs. external stimulation of sexual and aggressive behavior is evidenced by the differential ways in which motivational theorists have often conceptualized those systems. While sexuality is often classified as a "drive," implying internal stimulation, aggressive behavior or the underlying anger and hostility is more usually associated with emotion, implying elicitation by external stimulation (19). 
for reproduction due to internal sexual motivation, on the other hand, is far more likely to result in successfully passing on similar tendencies to later generations. The logic of the evolutionary process has thus favored the development of human sexual responses which are both internally and externally cued, but aggressive responses which are largely externally cued. These ideas would suggest that media violence should often have different effects than pornography, with the portrayal of violence sparking responses which might otherwise not have arisen at all, but with pornography stimulating responses which would have occurred eventually.

A somewhat related reason for suspecting different effects from stimulation by media depictions of sexuality or violence is derived from the different release patterns (from tension or arousal) possible with the two forms. There is no persuasive evidence that media depictions of violence lead to cathartic release; instead, the evidence suggests that in most media renditions of violent episodes, the balance of tension buildup and release favors, for most people, the buildup side. ${ }^{4}$ And it must be remembered that this aggression-related tension may not have arisen spontaneously, without the media depictions. With explicit sexuality, on the other hand, nonharmful cathartic effects are possible through sexual relations with a regular sexual partner, or through masturbation (7). It is meaningful to see explicit sexuality as an aid in cathartic release, since the sexual tensions may have developed as a result of internal needs existant prior to exposure to the explicit sexual material.

Timing factors of age and of the interval since the most recent involvement seem more relevant in determining the impact of explicit sexual materials than the impact of media violence. Preadolescent children seem to be less subject to strong influence by explicit sexuality since their ability to sustain sexual arousal is slight compared to their potential for feelings of anger. In commenting upon the (internal) British and Danish debates over the extent of media nudity and explicit sexuality which should be allowed, D. F. Barber (2) noted that "in Denmark there is convincing evidence that very young people quickly lose interest in pornography. They have less experience of shame and guilt to unlearn." We would, however, expect that adolescents would be greatly affected by their exposure to erotic materials, and we would expect that since this is both a formative period for attitudes about sexuality and a point which is near the height of sexual interest (at least for males, according to Kinsey (18)), that exposure or the lack of it might have long-term effects. The nature of those effects then becomes a central issue.

I should like to offer an alternative to the social learning model. This alternative has equal problems if over-extended, ${ }^{5}$ but this second model seems far more

${ }^{4}$ Although the issue of the possible cathartic release of hostility or tension associated with aggressive tendencies has been raised in one recent study (10), that study has been severely criticized $(20,22)$ and has failed to replicate $(23)$. The strongest conclusions which may be made about the effects of media violence are instead those made by the Violence Commission - that media violence increases tendencies toward aggression in many viewers (31).

${ }^{5}$ Social scientists frequently take their theoretical systems too seriously, attempting to extend models which are very adequate for organizing the knowledge in one area of human behavior into other areas which are not as amenable to that model. As suggested by George Kelly (16), each theoretical system has a limited range of convenience and point of focus. 
useful in interpreting some Pornography Commission data. In thinking about how individuals become preoccupied with certain types of stimulation or gratification after most of their contemporaries have adopted more mature levels of behavior, Freud (11) developed the dual concepts of positive and negative fixation. He suggested that if one is over-stimulated during certain critical periods in development with critical (for that period) types of gratification, one may remain preoccupied with that category of stimulation for longer than "normal" periods in development. This is termed positive fixation. This concept is one very similar to what a social learning view would predict for both sexuality and aggression, but it fits only the Violence Commission data. However, Freud also posited the opposite - that understimulation could also lead to preoccupation past the usual developmental period for such concern. Data gathered by Pornography Commission researchers Goldstein and Kant (15) concerning the underexposure (during adolescence) to explicit sexual information by those who are heavy users of pornography as adults suggests such a negative fixation or compensatory model.

Sex crime data support Freud's compensatory model, as do the Pornography Commission data on the early underexposure to explicit sexuality of sex criminals and adult pornography users. Evidence for the general impact of pornography upon our society is found in the sexual crime statistics as the volume of sexually oriented materials increased (7). Juvenile arrests for sex crimes declined 4 percent in this country from 1960 to 1969 , a period during which the Pornography Commission estimated that sexual materials increased several times; juvenile arrests for all crimes doubled during the same period. Additionally, the exposure of juvenile delinquents to all forms of erotic material was assessed as less than or equal to that of nondelinquents; certainly these data suggest no positive causal relationship between explicit sexual materials and any major category of juvenile crime. Pornography Commission researchers Goldstein and Kant $(7,15)$ have found that American male sexual offenders (rapists and child molesters) had generally been exposed to less explicit sexuality as adolescents than had normal controls. Nor do sexual offenders own or use more "pornography" as adults (13). Supporting data from Denmark indicated that sex crimes may have decreased with the legalization of pornography. According to Berl Kutchinsky of the Institute of Criminal Science at the University of Copenhagen, although people were just as likely to report sexual crimes such as child molestation, the incidence of that crime fell 63 percent between 1959 and 1970, with most of the decline after 1965, when hard-core pornographic magazines appeared in Denmark (26). Those data have been challenged recently in this Journal by Bachy (1), however, leaving the issue of support from the Denmark data somewhat in question. ${ }^{6}$

${ }^{6}$ By focusing on differences in sex crime statistics between those reported by Kutchinsky (26) (and used by the Pornography Commission (7), and later figures from the Copenhagen police, Victor Bachy (1) has suggested that it is impossible to determine if a reduction in actual sex crimes between 1965 and 1970 occurred. Although he correctly suggests that the apparent unreliability of the Copenhagen police records make the issue difficult to resolve, and although his data do cast some doubt upon conclusions from the Denmark experience, his argument is weakened by his use of data from such a limited period of years. That is, the Pornography Commission report (7) stated that in Denmark "lit- 
It is not difficult to suggest why explicit sexuality might have the beneficial effects of reducing sexual crime, but it is instructive that none of the explanations would make sense if we attempted to translate them to explain the effects of media violence. ${ }^{7}$

\section{Explicit media sexuality may provide needed sexual education and aid in the desensitization of deviance-producing tensions, allowing normal sexual patterns to emerge.}

Clinicians have suggested that sexual naivete is often implicated in deviant sexual practices (23). When the sexually naive adolescent uses inappropriate fantasy and imagery to accompany sexual feelings and/or masturbation, it is likely that those inappropriate images become the focus of a great deal more sexual attention and pleasure than they otherwise might. Some exposure to explicit sexuality during the adolescent or preadolescent years might be useful in reducing such naivete, particularly if meaningful or extensive sex education is lacking or minimal, as is usually the case in our society. Since the balance of types of pornography, reflecting consumer interest, is toward the depiction of nondeviant types of sexuality, the educational function cannot be seen as strongly reflecting or supporting deviant acts. And the educational function apparently does exist; in a national survey conducted for the Pornography Commission, 61 percent of the respondents indicated that pornography provided information about sex for people generally, and 24 percent indicated that it had provided new information about sex for them personally (28). Besides its information value, Goldstein and Kant (15) contend that it is often used to ward off unacceptable desires, particularly for convicted rapists. Furthermore, as suggested by the Pornography Commission Report, some exposure to the more deviant pornography may allay otherwise morbid curiosity.

But lack of important information is not the only problem caused by insufficient exposure to explicit sexual materials. The acquisition of associations between our sexuality and various negative emotions can also lead to serious problems in sexual adjustment. Not only did the research cited above (15) find that both rapists and child molesters were exposed to less pornography than normal

erary erotica has been available since 1965 and graphic material since 1967"; impressive data should therefore examine crime statistics from prior to 1965. The Pornography Commission indicated sex crime reduction by citing Ben Veniste's data indicating sharp reductions in sexual offenses between 1958 and 1969 in most important sex crime categories. Even Kutchinsky's data from between 1965 and 1969 do not indicate a convincing drop in sex crime during that period; Bachy's "revised" data do not therefore destroy a well-documented argument, for the argument was not well made by those data. Nevertheless, the point is well taken that any such data must be interpreted with caution.

${ }^{7}$ In addition to the obvious sexual component, rape involves extreme violence. In contrast to the evidence that exposure to explicitly sexual materials (during adolescence particularly) reduces the tendency to rape, it seems likely that media violence, portraying the virtues of the domination of the individuals, should encourage rape. This analysis is reinforced by the evidence supporting the compensatory model for exposure to explicit sexuality in contrast to the evidence that media violence increases violent behavior. 
controls during adolescence, but the sex offenders were more anxious and uncomfortable with sexuality as adults. Concentrating on rapists for a moment one can see easily how inability to discuss sex may contribute to their maladjustment. Some rapes occur between people who know each other, the rapist often asserting that his act was actually encouraged by his victim. If we conclude that such crimes sometimes occur as a result of a failure to communicate adequately about sexual needs and intent, we are again led to speculate that such problems might be partially remedied by exposure to explicitly sexual media. Exposure to sex education (or pornography) might be seen as having a similar effect on the potential child molester, who seems often to arrive at his method of sexual satisfaction through a failure to be able to engage in other more normal forms of sexuality.

In summary, with respect to the second level of apparent contradiction between the two Commissions' reports that both sexuality and violence would be stimulated in similar ways by explicit media portrayal, it has been argued that this apparent contradiction is due to underlying assumptions which are derived from a social learning view of humanity. But, that social learning model does not easily take into account vital differences between sexuality and violence as evolutionary products which are exposed in a cultural context. Differences between the balance in internal vs. external cues which stimulate aggression and sexuality are not considered by the model, nor is the fact that different types of media-induced cathartic behaviors are available for sexuality than for aggression. The model does not easily account for the obvious fact that explicit information should have different effects depending upon the extent and type of information presently available in the culture, and depending upon the extent of cultural pressure imposed to inhibit childhood sexuality (high) and violence (low) compared to the pressure imposed to inhibit adulthood sexuality (low) and violence (high). The finding of adult preoccupation with sexuality following adolescent deprivation of information is not compatible with the social learning model. Finally, the psychological and physiological readiness of individuals at different ages to respond to different types of stimulation is not taken into account by the social learning model.

But even when these biological and cultural factors are taken into account, we have considered a set of factors too limited to allow a complete understanding of the differential impact of media violence and pornography. A different but complementary approach to that taken in this article is to focus on the implicit messages usually transmitted in media presentations of violence or pornography. As suggested by Gerbner and Gross (14), one of the keys to understanding and predicting the impact of the media on attitudes and behavior is through a thorough analysis of the content of the projected message. Most televised violence, for example, suggests conflict between strangers, emphasizes the dominance and hierarchical relations between people, and is portrayed as far less painful than is the case in real life. The research of those authors suggests that the learning of the consumer reflects those salient aspects of such multivariate messages. Other characteristic dominance messages and statements about social and emotional relations between the sexes are evident in the "adults only" paperback (30) and in other pornography, though confirmation of the impact of such themes on the por- 
nography consumer via the research techniques developed by Gerbner and Gross has not (to my knowledge) been achieved. This focus on message content (rather than upon the characteristics of the recipient of the message) leads to similar conclusions - that we should not expect a complex message classified as a violent TV episode to have an impact upon the recipient which will be a "mirror image" of the impact created by a complex message labelled as explicit sexuality.

\section{Although the social learning model neither fits the Pornography Commission data nor relates to the obvious differences in sexual vs. aggressive responses, no single appropriate substitute model is available.}

The goal of science is usually to organize under a unifying theoretical system a great diversity of complex information which would have been unmanageable if not so systematized; but oversimplification is sometimes the result. At the present stage in the development of psychology and some other social sciences, progress will often stem from the elimination or elaboration of oversimplified theoretical systems.

Our assessment of the impact of exposure to violence and to explicit sexuality should rely primarily upon the available data. However, if our model of humanity and the beliefs implied by that model are not supported by those data, then we do have the right, perhaps the obligation, to raise the issue of bias in the data and in those who have gathered and interpreted those data, keeping in mind the possibility of biases in our own interpretations. But, however we balance and bias the available evidence, our conclusions will make little sense unless we consider the inherent nature of the human about whom we speculate, and the powerful forces of human culture.

It seems that a model of humanity which is more complex than the social learning model is necessary to account for the data of both the Pornography and Violence Commission findings, but we are left with no single model in replacement.

\section{If, in the best of all possible worlds, these arguments are correct and are accepted, the question remains as to how the recommendations of both Pornography and Violence Commissions should be effected, and what social and legal implications would result.}

Without advocating censorship, it is nevertheless tempting to speculate on the variables which should be considered in determining the extent of media presentations of explicit sexuality. If desensitization (i.e., reduced anxiety, shame, guilt, etc.) to sexual activities occurs for young people as a result of exposure to explicit sexual materials through sex education or through exposure to media sexuality, then we must assess whether such changes are desirable in our present society. Issues other than sex crimes loom with importance. There seems a need to maintain stability in the conjugal family as the child-rearing unit of our society, and to 
allow young people sufficient freedom from familial responsibilities to complete an extended education; illegitimate or unwanted children should be avoided, and population stability should be encouraged. Since the maintenance of those values depends in part upon the maintenance of some sexual control, we must ask whether control of the sexual behavior of young people through means other than maintaining ignorance, or instilling fear, disgust, and shame might be feasible. If wise decisions concerning sexual conduct are to be made by the individual as must ultimately be the case, then a maximum amount of relevant information must be available to the adolescent; wisdom does not easily result from ignorance.

Our typical sex education programs which stop with the presentation of physiological differences and the "plumbing" aspects of sexuality still leave the adolescent with far more questions than answers about sexual behavior. But until our society allows such extensive sex education programs to be made available to young people, explicit sexuality in the media may in part fulfill that function. The development of self-control may also be tied rather directly to exposure during adolescence to explicitly sexual materials. Goldstein and Kant (15) have suggested that the combination of sexually restrictive homes and underexposure to explicit sexuality may have resulted in a lack of experience in exercising sexual restraint for their deviant samples of rapists and child molesters.

The media may play a significant role, but again the differences in that role with sexuality and aggression become apparent. Since sufficient violence is already portrayed in news and factual programs to instigate any parent-child discussions about values relevant to violence (if such discussions are to occur at all), the vast amount of violence found in adventure, cartoon, and other fictionalized media presentations is superfluous for this purpose; it is overkill in all senses of that term. With respect to sexuality, however, the loosening of restrictions on nudity and other forms of explicit sexuality in the broadcast media in fictional programs could provide an opportunity for similar parent-child discussions of values, decisions, etc. Without the development of real sex education, such stimulation may provide the only opportunity many families will find to discuss sexuality in a meaningful manner.

\section{REFERENCES}

1. Bachy, Victor. “Danish 'Permissiveness' Revisited.” Journal of Communication, Winter 1976.

2. Barber, D. F. Pornography and Society. London: Charles Skilton, 1972.

3. Berkowitz, Leonard. "Sex and Violence: We Can’t Have it Both Ways." Psychology Today, December 1971.

4. Berns, Walter. "Beyond the (Garbage) Pale, or Democracy, Censorship and the Arts." In R. C. Rist (Ed.) The Pornography Controversy. New Brunswick: Transaction Books, 1975.

5. Blumenthal, Monica D., Robert L. Kahn, Frank M. Andrews, and Kendra B. Head. Justifying Violence: Attitudes of American Men. Ann Arbor: Institute for Social Research, 1972.

6. Bradshaw, Tom. "Why Indies Worry about 'Family Viewing."” Television/Radio Age, March, 3, 1975.

7. Commission on Obscenity and Pornography. Report of the Commission on Obscenity and Pornography. New York: Bantam Books, 1970. 
8. Comstock, George C. “The Evidence So Far.” Journal of Communication, Autumn 1975.

9. Eron, Leonard D., L. Rowell Huesmann, Monroe M . Lefkowitz, and Leopold O. Walder. "Does Television Violence Cause Aggression?" American Psychologist, April 1972.

10. Feshbach, Seymour and Robert D. Singer. Television and Aggression. San Francisco: Jossey-Bass, 1971.

11. Freud, Sigmund. The Standard Edition of the Complete Psychological Works of Sigmund Freud. Vol. 7: A Case of Hysteria and Three Essays on Sexuality. London: Hogarth Press, 1953.

12. Gagnon, John H, and William Simon. "Pornography_Raging Menace or Paper Tiger?” In R. C. Rist (Ed.) The Pornography Controversy. New Brunswick: Transaction Books, 1975.

13. Gebhard, Paul, John Gagnon, William Pomeroy, and Charles Christenson. Sex Offenders. New York: Harper and Row, 1965.

14. Gerbner, George and Larry Gross. "Living with Television: The Violence Profile." Journal of Communication, Spring 1976.

15. Goldstein, Michael J. and Harold S. Kant. Pornography and Sexual Deviance. Berkeley: University of California Press, 1973.

16. Kelly, George A. A Theory of Personality: The Psychology of Personal Constructs. New York: W. W. Norton, 1963.

17. Kilpatrick, James J. "Decriminalization: Pot, Yes; But Pornography? No!” In Lincoln Evening Journal, January 3, 1975.

18. Kinsey, Alfred C., Wardell B. Pomeroy, and Clyde E. Martin. Sexual Behavior in the Human Male. Philadelphia: W. B. Saunders, 1948.

19. Krech, David and Richard S. Crutchfield. Elements of Psychology. New York: Alfred A. Knopf, 1959.

20. Liebert, Robert M., Emily S. Davidson, and Michael P. Sobol. "Catharsis of Aggression Among Institutionalized Boys: Further Comments.” In G. A. Comstock. E. A. Rubinstein, and J. P. Murray (Eds. ) Television and Social Behavior, Reports and Papers, Vol. 5: Television's Effects: Further Explorations. Rockville: National Institute of Mental Health, 1972.

21. Liebert, Robert M, and John M. Neale. The Early Window: Effects of Television on Children and Youth. New York: Pergamon Press, 1973.

22. Liebert, Robert M., Michael D. Sobol, and Emily S. Davidson. "Catharsis of Aggression Among Institutionalized Boys: Fact or Artifact?” In G. A. Comstock, E. A. Rubinstein, and J. P. Murray (Eds.) Television and Social Behavior, Reports and Papers, Vol. 5: Television's Effects: Further Explorations. Rockville: National Institute of Mental Health, 1972.

23. McCary, James Leslie. Human Sexuality. New York: Van Nostrand, 1973.

24. Mischel, Walter. Introduction to Personality. New York: Holt, 1971.

25. National Commission on the Causes and Prevention of Violence. To Establish Justice, to Insure Domestic Tranquility. New York: Award Books, 1969.

26. "Post-Porno Denmark.” Human Behavior, January 1974.

27. Rist, Ray C. "Polity, Politics and Social Research: A Study in the Relationship of Federal Commissions and Social Science.” In R. C. Rist (Ed.) The Pornography Controversy. New Brunswick: Transaction Books, 1975.

28. Rist, Ray C. "Pornography as a Social Problem: Reflections on the Relation of Morality and the Law." In R. C. Rist (Ed.) The Pornography Controversy. New Brunswick: Transaction Books, 1975.

29. Rushdoony, Rousas J. The Politics of Pornography. New Rochelle: Arlington House Publishers, 1974.

30. Smith, Don D. "The Social Content of Pornography." Journal of Communication, Winter 1976.

31. Surgeon General's Scientific Advisory Committee on Television and Social Behavior. Television and Growing Up: The Impact of Televised Violence. Washington, D.C.: U.S. Government Printing Office, 1971.

32. "Wiley Plan to Clean Up Television Goes to Hill." Broadcasting, February 24, 1975.

33. Wilson, James Q. "Violence, Pornography and Social Science.” In R. C. Rist (Ed.) The Pornography Controversy. New Brunswick: Transaction Books, 1975. 